\title{
High Frequency Transcricoid Jet Ventilation Prior to Neck Surgery-A 10-Year Retrospective Case Series Analysis
}

\author{
Hille Kisch-Wedel ${ }^{*}$ (D) Hannelore Ledderose, Kathrin Reise, Bernhard Zwissler \\ Department of Anesthesiology, University Hospital, LMU Munich, Marchioninistr, Munich, Germany \\ Email: *hkisch@med.uni-muenchen.de
}

How to cite this paper: Kisch-Wedel, H., Ledderose, H., Reise, K. and Zwissler, B. (2020) High Frequency Transcricoid Jet Ventilation Prior to Neck Surgery-A 10-Year Retrospective Case Series Analysis. Open Journal of Anesthesiology, 10, 38-45.

https://doi.org/10.4236/ojanes.2019.101004

Received: December 17, 2019

Accepted: January 18, 2020

Published: January 21, 2020

Copyright $\odot 2020$ by author(s) and Scientific Research Publishing Inc. This work is licensed under the Creative Commons Attribution International License (CC BY 4.0).

http://creativecommons.org/licenses/by/4.0/

\begin{abstract}
Difficult airway is still a challenging field in anesthesia, emergency departments and intensive care unit and is the cause of severe patient injury such as irreversible hypoxic brain damage or even death. Therefore, safer techniques are needed to maintain the airway in patients, who are difficult to intubate. The aim was to analyze the safety of the technique of transcricoid high frequency jetventilation (TCHFJV) by the investigation of complications. We performed a 10-year retrospective analysis (1/2009-1/2019) of patients subjected to TCHFJV at the hospital of the Ludwigs-Maximilians-University, Munich, Germany. TCHFJV was applied before anesthesia induction in awake, spontaneously breathing patients, with suspected or known difficult airway, scheduled for head and neck surgery. During the 10-year study period, we identified 39,477 patients, who underwent neck surgery. Of these, 1489 (3.8\%) patients were managed with TCHFJV (1090 males, 399 females; $62 \pm 13$ years, BMI $25 \pm 0.2 \mathrm{~kg} \cdot \mathrm{m}^{-2}$, ASA class $\left.3 \pm 0.5\right)$. TCHFJV was successful in 1479 (99\%) patients. Subsequent endotracheal intubation was performed in most cases (93\%). Occasionally, emergency cricothyroidotomy ( $\mathrm{n}$ $=2)$ or tracheotomy $(n=6)$ was necessary following TCHFJV. TCHFJV-related complications occurred in $1.5 \%$ of the cases. A majority (83\%) of the complications were judged to be non-severe (grade $1,2^{\mathrm{A}}$ ) and $17 \%$ were severe (grade $3^{\mathrm{B}}$ ), while there were none that were very severe ${ }^{\mathrm{C}}$ or lethal $\mathrm{l}^{\mathrm{D}}$. This retrospective study indicates that TCHFJV in experienced hands is a relatively safe alternative airway management strategy for patients undergoing neck surgery.
\end{abstract}

\footnotetext{
${ }^{\mathrm{A}}$ Complication grade 1: without relevance for the care in the recovery room.

Complication grade 2: with relevance for the care in the recovery room, without relevance for further care.

${ }^{\mathrm{B}}$ Complication grade 3: with relevance for the care in the recovery room, longer observation required.

${ }^{\mathrm{C}}$ Complication grade 4 : intensive care required.

${ }^{\mathrm{D} C o m p l i c a t i o n}$ grade 5: death.
} 


\section{Keywords}

Jetventilation, Transcricoid, Difficult Airway

\section{Introduction}

\subsection{Background}

The management of the difficult airway is challenging, because the problem has to be solved within 3 minutes to prevent hypoxic brain damage or death. Adverse outcomes of airway problems are by no means rare: A recent study conducted in the UK and comprising 184 recorded events in intensive care units or emergency departments documented that $61 \%$ of these events resulted in death or persistent neurological damage [1]. When focusing on anesthesia, 16 deaths and three episodes of persistent brain damage were due to complications of airway management in this study. $19 \%$ of airway complications were considered to be related to anesthesia [2]. An underestimated option for the management of the anticipated difficult airway is transcricoid high frequency jetventilation (TCHFJV), which was derived from the earliest described ventilation type: air insufflation. In reports going back as far as 1671, air insufflation was described to prolong the survival of dogs [3]. Centuries later, Jacoby et al. described the first transtracheal high frequency ventilation, which was interrupted air insufflation, in 5 patients with oropharyngeal/laryngeal tumors [4]. The patients suffered from airway obstruction and diminished oxygen saturation after sedation. Immediate transtracheal resuscitation with TCHFJV restored oxygen saturation [4] [5]. In 1999 Patel [6] and his team applied TCHFJV in intensive care patients, where mask ventilation or intubation in two or three attempts was impossible. TCHFJV was achieved successfully in over $80 \%$ of the cases and time was gained to secure the airway by alternative procedures, which were mainly intubations with special material, but also tracheotomies or coniotomies [6]. TCHFJV was favored in the 70 ies, but TCHFJV was highly questionable due to complications later. However, TCHFJV is still recommended by the ASA for invasive airway management [7]. Thus, the improvement of airway management is still an important topic in anesthesia, intensive care and emergency medicine.

\subsection{Objective}

Surgical cricothyroidotomy is a final common rescue option for the "can't intubate can't ventilate" situation [8]. However, it may be difficult or unsuccessful, in part because of the urgency of the situation coupled with operator inexperience [8]. At the University hospital of the LMU Munich, Germany, transcricoid high-frequency jetventilation is routinely used as a part of the airway management preceding neck surgery for tumors that impact on the upper airway [9]. Following local ethics board approval (19-711), data were collected retrospec- 
tively (1/2009-1/2019) from an anesthesia documentation system (Narcodata ${ }^{\circledR}$, IMESO, Germany) to test: Is TCHFJV a safe airway management option? How many and which complications occurred?

\section{Methods}

TCHFJV was performed by a staff anesthesiologist or by a supervised trainee. The goal was to insert a ventilating catheter through the cricothyroid membrane (CTM) in an awake, spontaneously breathing patient, and initiate high frequency jetventilation prior to induction of general anesthesia. Sedation was usually achieved with a small dose of sufentanil ( $5 \mu \mathrm{g}$ iv). Local anesthetic ( $4 \mathrm{ml}$ of $2 \%$ lidocaine) was injected through the CTM, located by palpation, with a small needle ( 23 gauge, $25 \mathrm{~mm}$ ) into the trachea [10]. The CTM was punctured using a loss of resistance technique, and needle placement was verified by positive air aspiration. A linear ultrasound probe was used occasionally for the location of the CTM, if it was difficult to identify. A guide wire was subsequently inserted into the needle, and then after dilatation, a single lumen central venous 14 gauge catheter ( $20 \mathrm{~cm}$ length, Arrow, Carrington, USA) was advanced over the wire into the trachea (Seldinger technique). The catheter was inserted approximately $13-15 \mathrm{~cm}$ beyond the skin and secured with tape. The catheter was connected to a Monsoon jetventilator (Acutronic, Hirzel, Switzerland) and jetventilation was achieved with these respiratory settings: ventilation frequency of 100 per minute, driving pressure of 1 - 2 bar (1300 - $\left.2600 \mathrm{cmH}_{2} 0\right)$, upper pressure level 50 mbar $\left(65 \mathrm{cmH}_{2} \mathrm{O}\right)$ and inspiration time of $30 \%-40 \%$. General anesthesia was not induced, if TCHFJV failed. Indications for successful initiation of TCHFV included appropriate chest wall auscultation (stethoscope) and movement coincident with high frequency ventilation, and ventilating pressures below 50 mbar (65 $\mathrm{cmH}_{2} \mathrm{O}$ ) (avoidance of high-pressure alarm triggers). In cases, where TCHFJV failed, the airway was secured by awake fiberoptic intubation (FOI) or surgical tracheotomy (local anesthesia infiltration). A separate group of 17 patients received only a TCHFJV (TCHFJV only) without intubation and without conventional ventilation for the surgical procedure of opening a subglottic stenosis. Then the respiratory air was humidified. The driving pressures of the jetventilator were increased for TCHFJV only from $1.5\left(1950 \mathrm{cmH}_{2} \mathrm{O}\right)$ to maximally 3.5 bar $\left(4550 \mathrm{cmH}_{2} \mathrm{O}\right)$ adjusted to arterial blood gas analysis. These $17 \mathrm{pa}-$ tients had a median age of $62 \pm 6$ years. 7 were males and 10 females with a median weight of $74 \pm 6.5 \mathrm{~kg}$, a median height of $168 \pm 4.5 \mathrm{~cm}$, and a median ASA-PS classification of $3 \pm 0.5 .3$ patients out of 17 (18\%) had to be tracheotomized. Arterial blood gas analyses (Table 1) were performed up to 3 times.

\section{Measurements and Statistical Methods}

Physiological data (heart rate from the electrocardiogram, systolic, mean and diastolic blood pressure from noninvasive blood pressure measurement, arterial oxygen saturation from a noninvasive peripheral pulse oximeter, endtidal carbon dioxide from the standard ventilator following TCHFJV) were averaged 
Table 1. TCHFJV only: Arterial blood gas analysis.

\begin{tabular}{ccccccccc}
\hline & Time 1 & $\mathrm{n}$ & Time 2 & $\mathrm{n}$ & $\mathrm{p}$ & Time 3 & $\mathrm{n}$ & $\mathrm{p}$ \\
\hline Time (min) & $26 \pm 5$ & 17 & $43 \pm 11$ & 9 & & $52 \pm 17$ & 4 & not tested \\
$\mathrm{paO}_{2}(\mathrm{mmHg})$ & $410 \pm 64$ & 15 & $400 \pm 100$ & 8 & $\mathrm{~ns}$ & $372 \pm 77$ & 4 & $\mathrm{~ns}$ \\
$\mathrm{paCO}_{2}(\mathrm{mmHg})$ & $42 \pm 17$ & 15 & $40 \pm 11$ & 8 & $\mathrm{~ns}$ & $47.15 \pm 8$ & 4 & $\mathrm{~ns}$ \\
$\mathrm{pH}$ & $7.413 \pm 0.004$ & 17 & $7.459 \pm 0.1$ & 9 & $\mathrm{~ns}$ & $7.349 \pm 0.106$ & 4 & $\mathrm{~ns}$ \\
$\mathrm{SaO}_{2}(\%)$ & $99.8 \pm 0.15$ & 15 & $99.75 \pm 0.2$ & 8 & $\mathrm{~ns}$ & $99.7 \pm 0.025$ & 4 & $\mathrm{~ns}$ \\
$\begin{array}{c}\text { Base excess (mmol/l) } \\
\text { Standard bicarbonate }\end{array}$ & $1.3 \pm 1.5$ & 17 & $1.6 \pm 1.5$ & 9 & $\mathrm{~ns}$ & $1.1 \pm 1.8$ & 4 & $\mathrm{~ns}$ \\
\begin{tabular}{c} 
(mmol/l) \\
\hline
\end{tabular} & $26.1 \pm 1.2$ & 13 & $26.3 \pm 1$ & 6 & $\mathrm{~ns}$ & $25.1 \pm 2.6$ & 3 & $\mathrm{~ns}$ \\
\hline
\end{tabular}

Legend: Data are presented as median \pm semi-interquartiles range; ${ }^{*} \mathrm{p}<0.05$ Wilcoxon signed rank test, ns: not significant; $\mathrm{n}$ : number; $\mathrm{paO}_{2}$ : arterial oxygen partial pressure; $\mathrm{paCO}_{2}$ : arterial carbon dioxide pressure; $\mathrm{SaO}_{2}$ : arterial oxygen saturation.

over the 10-minute interval just prior to and after TCHFJV (following TCHFJV). Data are presented as mean \pm standard deviation (SD) or $95 \%$ confidence interval (CI). Gaussian distribution was demonstrated for pairwise data (Shapiro-Wilks test), and data were compared prior to and following TCHFJV using the paired t-tests. The subgroup of 17 patients with TCHFJV only failed Gaussian distribution and data were presented as median \pm semi-interquartile range tested with Wilcoxon signed rank tests. A probability level $\mathrm{P}<0.05$ was considered to be statistically significant. The Cormack classification, type of intubation, age, height, body weight, documentation of complications and all other descriptive data were read out of an anesthesia documentation system and patient data (Narcodata ${ }^{\oplus}$ IMESO, Germany) and imported into an excel sheet (completely anonymized).

\section{Results}

\section{Study Design/Settings and Participants}

During the 10-year study period, we identified 39,477 patients, who underwent neck surgery. Of these, 1489 patients were managed with TCHFJV (1090 males, 399 females; $62 \pm 13$ years, BMI $25 \pm 0.2 \mathrm{~kg} \cdot \mathrm{m}^{-2}$, ASA class $3 \pm 0.5$ ). The majority (91\%) of the patients were scheduled for elective head and neck tumor surgery, while $9 \%$ were emergency cases. TCHFJV was successful in 1479 (99\%) patients. Subsequent endotracheal intubation was performed in most cases $(\mathrm{n}=1368$ (93\%) patients, average Cormack Lehane (CL) grade $3 \pm 1$; CL grade 1: $26 \%$; CL grade 2: 28\%; CL grade 3: 19\%, CL grade 4: 6\%, CL grade not classified 20\%). Sixty-four percent of intubations were performed by direct laryngoscopy, 30\% by videolaryngoscopy and $3 \%$ with a fiberoptic bronchoscope. In $17 \%$ of cases, tracheal intubation could not be achieved due to airway pathology. In those cases, surgery was performed using TCHFJV (TCHFJV only, arterial blood gas analysis, Table 1).

Thirty-two percent of the patients underwent planned surgical tracheostomy. 
Occasionally, emergency cricothyroidotomy $(n=2)$ or tracheotomy $(n=6)$ were necessary following TCHFJV.

The mean time required to establish TCHFJV (injection of local anesthesia to jet ventilation) was $9 \pm 18 \mathrm{~min}$. Following TCHFJV, end-tidal carbon dioxide was in a physiological range (Table 2). Following TCHFJV, there was a slight reduction in blood pressure (mean, systolic, diastolic) and heart rate, and an increase in peripheral oxygen saturation (Table 2 ).

TCHFJV-related complications occurred in $1.5 \%$ of the cases $(23 / 1489$, Table 3 ). The majority (83\%) of the complications were judged to be non-severe (grade $1,2^{\mathrm{A}}$ ) and $17 \%$ were severe $\left(\operatorname{grade}^{3 \mathrm{~B}}\right.$ ) while there were none were very severe ${ }^{\mathrm{C}}$ or lethal $^{\mathrm{D}}$ [11]. Intraoperative complications included bleeding $(\mathrm{n}=4$, grade $2-3)$, TCHFJV abandoned due to high pressure alarm $(n=2$, grade 2$)$. Failed intubation besides TCHFJV ( $\mathrm{n}=2$, grade1), symptomatic pneumomediastinum $(\mathrm{n}=2$, grade 3 ) and infection $(n=2$, grade 1$)$.

\section{Discussion}

TCHFJV for the management of difficult intubation is performed nowadays rarely. Although, TCHFJV was reported in the 1970 and later by several authors (for example: [4] [5] [6] [12] [13]). In contrast, this procedure is not performed routinely in clinical anesthesia. The reason is possible complications: wrong position of the jet probe may lead to life threatening complications such as tracheal compression [14], severe mediastinal emphysema, pneumothorax, severe bleeding, obstruction of the jet probe by kinking or compression. Further problems were air entrainment or severe hypotonia. Still, TCHFJV is recommended as an invasive procedure equally to coniotomy to manage unexpected difficult airway by the ASA [7]. It is difficult to perform a TCHFJV in an emergency situation, if it was not practiced before routinely. The data of the present retrospective study clearly show that preemptive TCHFJV had few severe complications

Table 2. Hemodynamics, arterial oxygen saturation, end tidal carbon dioxide $10 \mathrm{~min}$ prior to and following TCHFJV and anesthesia induction.

\begin{tabular}{|c|c|c|c|c|c|c|c|c|c|c|c|c|c|c|c|c|}
\hline \multirow[b]{2}{*}{$\begin{array}{l}\text { Blood } \\
\text { pressure }\end{array}$} & \multicolumn{5}{|c|}{ Prior to TCHFJV } & \multicolumn{5}{|c|}{ Following TCHFJV } & \multicolumn{6}{|c|}{$\mathrm{p}<0.05$ (paired t-tests) * } \\
\hline & Mean & $(95 \% \mathrm{CI})$ & Lower & to & $\begin{array}{l}\text { Upper } \\
\text { level }\end{array}$ & Mean & $(95 \% \mathrm{CI})$ & Lower & to & $\begin{array}{l}\text { Upper } \\
\text { level }\end{array}$ & $\mathbf{n}$ & $\begin{array}{c}\text { Mean } \\
\text { difference }\end{array}$ & $(95 \% \mathrm{CI})$ & Lower & to & $\begin{array}{l}\text { Upper } \\
\text { level }\end{array}$ \\
\hline Systolic & 140.0 & $(1.2)$ & 138.8 & to & 141.2 & 132.6 & $(1.2)$ & 131.3 & to & 133.8 & 1392 & -7.5 & $(1.1)$ & -8.6 & to & $-6.4^{*}$ \\
\hline Mean & 107.1 & $(0.9)$ & 106.2 & to & 108.0 & 101.4 & $(1.0)$ & 100.5 & to & 102.4 & 1382 & -5.8 & $(0.8)$ & -6.7 & to & $-5.0^{*}$ \\
\hline Diastolic & 82.5 & $(0.7)$ & 81.7 & to & 83.2 & 78.6 & $(0.8)$ & 77.8 & to & 79.4 & 1392 & -4.0 & $(0.6)$ & -4.7 & to & $-3.4^{*}$ \\
\hline Heart rate & 81.9 & $(0.9)$ & 81.0 & to & 82.8 & 79.9 & $(0.9)$ & 78.9 & to & 80.8 & 1452 & -2.1 & $(0.6)$ & -2.7 & to & $-1.5^{\star}$ \\
\hline $\begin{array}{l}\text { Arterial oxygen } \\
\text { saturation }\end{array}$ & 96.8 & $(0.2)$ & 96.6 & to & 97.0 & 98.4 & $(0.1)$ & 98.3 & to & 98.6 & 1324 & 1.6 & $(0.2)$ & 1.4 & to & $1.8^{*}$ \\
\hline $\begin{array}{c}\text { End tidal } \\
\text { carbon dioxide }\end{array}$ & & & & & & 32 & $(0.2)$ & 31.5 & to & 31.8 & 1277 & & & & & \\
\hline
\end{tabular}

n: number of patients, $95 \% \mathrm{CI}: 95 \%$ confidence interval. 
Table 3. Complications and transcricoid high frequency jetventilation (TCHFJV).

\begin{tabular}{ccc}
\hline & $\mathrm{n}=$ & $\%$ \\
\hline Total anesthesias & 39,477 & 3.8 \\
Total TCHFJVs & 1489 & \\
Bleeding & & $\mathbf{0 . 2}$ \\
Failed intubation besides TCHFJV (intraoperative (io)) & 2 & 0.1 \\
TCHFJV impossible due to pressure alarm (io) & 1 & 0.1 \\
Symptomatic pneumomediastinum (po) & 2 & 0.1 \\
Infection (po) & 2 & 0.1 \\
Other observations (io and po) & 2 & 0.1 \\
Total complications & 10 & 0.7 \\
Non-severe (grade 1, 2) & 23 & 1.5 \\
Severe (grade 3) & 19 & 83 \\
Very severe (grade 4) & 4 & 17 \\
Letal (grade 5) & 0 & 0 \\
\hline
\end{tabular}

Legend: po: postoperative; io: intraoperative; io and po: intraoperative and postoperative. Complication grade 1: without relevance for the care in the recovery room; complication grade 2: with relevance for the care in the recovery room, without relevance for further care; complication grade 3: with relevance for the care in the recovery room, longer observation required; complication grade 4: intensive care required; complication grade 5: death.

(4/1489, 0.3\%, Table 3). Requirements for TCHFJV were Seldinger technique, a jetventilator with adapted ventilation pattern and preemptive application. Indication for preemptive TCHFJV was anesthesias for patients with upper airway pathologies, which impact on the airway $(n=1489)$, typically T3/T4 oropharyngeal and laryngeal tumors Jetventilation was provided up to 50 minutes: in the subgroup of the 17 patients with subglottic stenosis: arterial oxygen partial pressure, arterial carbon dioxide pressure and arterial $\mathrm{pH}$ were kept constant for 50 minutes (Table 1, ns). Thus, time was gained by TCHFJV to perform other procedures properly, including difficult intubation, emergency tracheotomy or, in single cases, emergency coniotomy. This is a step to more patient safety for patients with difficult airway: hypoxic brain damage or death had not occurred perioperatively in our study group of 1489 patients. This confirms that TCHFJV is not only an emergency tool to maintain ventilation during a difficult intubation. The data of the present retrospective study show that preemptive TCHFJV has few severe complications, typically bleeding (Table 3 ) and provided ventilation up to 50 minutes (Table 1). In conclusion, preemptive TCHFJV is a safe tool for routine management of the difficult airway of patients prior to anesthesia for neck surgery. 


\subsection{Limitations}

Limitations of the study are the single center and retrospective design. Besides, 1489 patients out of 39,477 and a decade of study period were not reported before. The long study period additionally to the single center design allows for standard and expert performance. In contrast, [14] investigated only 428 procedures in 44 different studies and concluded: "TTJV is associated with a high risk of device failure and barotrauma in the CICO emergency. Guidelines and recommendations supporting the use of TTJV in CICO should be reconsidered." (TTJV: transtracheal jetventilation).

\subsection{Generalisibility}

This retrospective study indicates that TCHFJV in experienced hands, is a relatively safe alternative airway management strategy for patients undergoing neck surgery. Moreover, anesthesiologists experienced with this technique are also well-prepared to manage the "can't intubate can't ventilate" scenario, when expeditious surgical access to the trachea can be life-saving.

\section{Acknowledgements}

We greatly acknowledge the anesthesia patient care and neck surgery team (head Prof. Martin Canis and Alexander Berghaus (emeritus), LMU Munich, Marchioninistr. 15, D-81377 Munich, Germany). Special thanks to Renate Neitzert and Pia Günther for their excellent assistance in performing jet-ventilations and to our data processing team, Richard Spitz (MD), Ludwig Christian Hinske (MD) and Sebastian Niedermayer (MD) for provision of the data stored in the patient data management system.

\section{Conflicts of Interest}

The authors declare no conflicts of interest regarding the publication of this paper.

\section{References}

[1] Cook, T.M., Woodall, N., Harper, J., Benger, J., on Behalf of the Fourth National Audit Project (2011) Major Complications of Airway Management in the UK: Results of the Fourth National Audit Project and the Difficult Airway Society Part 2: Intensive Care and Emergency Departments. British Journal of Anaesthesia, 106, 632-642. https://doi.org/10.1093/bja/aer059

[2] Cook, T.M., Woodall, N., Frerk, V., on Behalf of the Fourth National Audit Project of the Royal College of Anaesthesists and the Difficult Airway Society (2011) Part 1: Anesthesia. British Journal of Anaesthesia, 106, 617-631. https://doi.org/10.1093/bja/aer058

[3] Hooke, R. (1671) Account of Experiment Made by R. Hooke, of Preserving Animals Alive by Blowing through Their Lungs with Bellows. Philosophical Transactions of the Royal Society of London, 2, 539-540. https://doi.org/10.1098/rstl.1666.0043

[4] Jacoby, J.J., Hamelberg, W., Ziegler, C.H., Flory, F.A. and Jones, J.R. (1956) Trans- 
tracheal Resuscitation. JAMA, 162, 625-628.

https://doi.org/10.1001/jama.1956.02970240007003

[5] Biro, P. and Moe, K.S. (1997) Emergency Transtracheal Jetventilation in High Grade Airway Obstruction. Journal of Clinical Anesthesia, 9, 604-607.

https://doi.org/10.1016/S0952-8180(97)00158-X

[6] Patel, R.G. (1999) Percutaneous Transtracheal Jetventilation. Chest, 116, 1689-1694. https://doi.org/10.1378/chest.116.6.1689

[7] Apfelbaum, J.L., Hagberg, C.A., Caplan, R.A., Blitt, C.D., Connis, R.T., Nickinovich, D.G., Hagberg, C.A., Caplan, R.A., Benumof, J.L., Berry, F.A., Blitt, C.D., Bode, R.H., Cheney, F.W., Connis, R.T., Guidry, O.F., Nickinovich, D.G. and Ovassapian, A., (2013) Practice Guidelines for Management of the Difficult Airway: An Updated Report by the American Society of Anesthesiologists Task Force on Management of the Difficult airway. Anesthesiology, 118, 251-270. https://doi.org/10.1097/ALN.0b013e31827773b2

[8] Pracy, J.P., Brennan, L., Cook, T.M., Hartle, A.J., Marks, R.J., McGrath, B.A., Narula, A. and Patel, A. (2016) Surgical Intervention during a Can't Intubate Can't Oxygenate (CICO) Event: Emergency Front-of-Neck Airway (FONA)? British Journal of Anaesthesia, 117, 426-428. https://doi.org/10.1093/bja/aew221

[9] Kisch-Wedel, H. (2014) Transtracheal Jetventilation an Underestimated Option (Transtracheale Jetventilation eine unterschätzte Option). Anästh Intensivmed, 55, S445.

[10] Bonica, J. (1949) Transtracheal Anesthesia for Endotracheal Intubation. Anesthesiology, 10, 736-738. https://doi.org/10.1097/00000542-194911000-00010

[11] Bothner, U., Georgieff, M. and Schwilk, B. (2000) Building a Large-Scale Perioperative Outcome-Tracking Database: Methodology, Implementation, and Experiences from One Provider within the German Quality Project. British Journal of Anaesthesia, 85, 271-280. https://doi.org/10.1093/bja/85.2.271

[12] Spoerel, W., Narayanan, P. and Singh, N. (1971) Transtracheal Ventilation. British Journal of Anaesthesia, 43, 932-939. https://doi.org/10.1093/bja/43.10.932

[13] Klain, M. and Smith, R.B. (1977) High Frequency Percutaneous Transtracheal Jetventilation. Critical Care Medicine, 5, 280-287. https://doi.org/10.1097/00003246-197711000-00007

[14] Duggan, L.V., Scott, S.B., Law, J.A., Morris, I.R., Murphy, M.F. and Griesdale, D.E. (2016) Transtracheal Jet Ventilation in the "Can't Intubate Can'T Oxygenate" Emergency: A Systematic Review. British Journal of Anaesthesia, 117, i28-i38. https://doi.org/10.1093/bja/aew192 